\title{
Scaling issues in the interpretation of dry matter yield differences among perennial ryegrass (Lolium perenne) cultivars
}

\author{
David F. CHAPMAN ${ }^{1 *}$, Gerald P. COSGROVE², Barbara KUHN-SHERLOCK ${ }^{3}$, David R. STEVENS 4 , \\ Julia M. LEE ${ }^{3}$ and Laura ROSSI ${ }^{3}$ \\ ${ }^{1}$ DairyNZ, Canterbury Agriculture and Science Centre, PO Box 85066, Lincoln 7647, New Zealand \\ ${ }^{2}$ AgResearch Ltd., Grasslands Research Centre, PB11008, Palmerston North 4442, New Zealand \\ ${ }^{3}$ DairyNZ, Private Bag 3221, Hamilton 3420, New Zealand \\ ${ }^{4}$ AgResearch Ltd., Invermay Research Centre, PB50034, Mosgiel 9053, New Zealand \\ *Corresponding author: david.chapman@dairynz.co.nz
}

\begin{abstract}
Perennial ryegrass breeding is estimated to be delivering rates of genetic gain in dry matter (DM) yield of 50-60 $\mathrm{kg} \mathrm{DM} / \mathrm{ha}$ per year of breeding effort. These estimates are based on DM yield data from tightly managed smallplot trials which are not necessarily representative of typical farm management. To assess the possible realised (on-farm) DMY gains from breeding, seasonal DMY data were collected contemporaneously at two 'scales' of evaluation for eight perennial ryegrass cultivars over a total of 14 seasons (comprising 5 'seasons' in each of three years excluding the first winter) in each of four regions. The scales were denoted 'small plot' (SP, 10 $\mathrm{m}^{2}$, perennial ryegrass monocultures only) and 'large plot' (LP, 65-90 $\mathrm{m}^{2}$, subject to more intensive dairy cattle grazing and including all combinations of two nitrogen fertiliser rates with or without white clover as treatments). Relationships between DMY measured in SP versus LP were statistically significant $(\mathrm{P}<0.001)$ for all combinations of region, $\mathrm{N}$ fertiliser level and clover presence/absence, indicating good general agreement in cultivar performance trends. However, the slope of the relationship (range 0.492 to 1.171 , mean 0.733 ) was significantly less than 1 in three-quarters of the region by treatment combinations. The slope was closely and inversely related to the size of the difference in total $\mathrm{N}$ supply between and SP (N from fertiliser only) and LP (where $\mathrm{N}$ was supplied as fertiliser at a lower rate but included biological fixation): the smaller the difference in $\mathrm{N}$ supply between the two 'scales', the greater the slope. Estimated realised DMY differences between cultivar ranking positions on New Zealand dairy farms under future projected $\mathrm{N}$ fertiliser rates were in the range $0.7-0.8$ of those predicted from the SP scale of evaluation.
\end{abstract}

Keywords: genetic gain, forage evaluation, pasture management, nitrogen

\section{Introduction}

The evaluation of the performance of perennial ryegrass cultivars in New Zealand (NZ) is based on the National Forage Variety Trial system administered by the NZ Plant Breeding and Research Association (NZPBRA). National Forage Variety Trial (NFVT) data are used directly in the DairyNZ Forage Value Index (FVI) to calculate performance values for cultivarspecific seasonal dry matter yield (DMY) which are then combined with economic values for the DMY traits to calculate an overall FVI and rank order for each cultivar in four mega-regions encompassing the national dairy industry (Chapman et al. 2017). Trials are typically conducted in $5 \mathrm{~m} \times 2 \mathrm{~m}$ plots under a welldocumented management and measurement protocol which specifies key rules such as trial duration (3 years for perennial ryegrass), defoliation method (mostly grazing by sheep or cattle, though some trials are mown only), defoliation management (common residual pasture heights are maintained across all cultivar entries, facilitated by topping after grazing if necessary in the case of grazing trials), and nitrogen $(\mathrm{N})$ fertiliser rates ( $\mathrm{N}$ application per plot must equal $3 \%$ of total $\mathrm{DM}$ removed). The NFVT protocols have been developed to, as far as possible, minimise management-related effects that could bias or obscure genetic differences in DMY; on the reasonable premise that the core purpose of the trials is to measure the relative genetic merits of cultivars and hence the relative success of breeding programmes.

Based on NFVT data (or equivalent evaluation systems), it has been estimated that perennial ryegrass breeding is delivering rates of genetic gain in DMY of $\sim 0.3$ to $0.8 \%$ per year (Lee et al. 2012; Harmer et al. 2018). In the FVI, these translate to estimated gains in farm profit of \$15-\$20 per hectare per year of breeding effort (Chapman et al. 2017). Furthermore, the FVI estimates that dairy farm businesses based on high-ranking cultivars will deliver several hundred dollars per hectare greater profit each year compared with businesses based on lower ranked cultivars. However, there is no information available to gauge the realised (i.e. on-farm) difference in DMY between cultivars in different ranking positions within the FVI, and therefore the profit differences that farmers could expect to capture in practice.

Given that the NFVT protocols purposely seek 
to minimise effects of management practices that might obscure cultivar DMY differences, the counterfactual is that those differences will be diluted as the management factors come into play. It is important to know if this is, indeed, the case so that: (1) farmers can have confidence that indexing systems such as the FVI represent the true economic benefit of ryegrass cultivar development to their businesses; and (2) industry support organisations are confident that current evaluation systems are adequately representing the 'real world'.

This paper reports a comparison of the relative performance of a common group of eight perennial ryegrass cultivars from two 'scales' of evaluation: one based on small plots managed and measured using protocols similar to those used in NFVT; and one based on larger plots sizes, more intensive dairy cattle grazing, presence or absence of clover, and different rates of $\mathrm{N}$ fertiliser input. All of the trials were still under a high degree of management and measurement (befitting the research objectives behind them) albeit with different protocols. The objective was to determine how well small plot methods using a single management protocol 'predict' relative DMY at larger scales under different managements and, from this, assess likely realised rates of genetic gain in current and future dairy systems.

\section{Materials and Methods \\ Trials}

The two 'scales' of evaluation were: small $\left(10 \mathrm{~m}^{2}\right)$ plots, denoted 'SP', and larger research plots (ranging from $65 \mathrm{~m}^{2}$ to $90 \mathrm{~m}^{2}$ depending on location of the trial), denoted 'LP'. Pastures in the SP trial were sown as perennial ryegrass monocultures and were maintained in that state through application of herbicides as required to prevent ingress of white clover and other broad-leaved species.

Large plots (LP) were nested within the 'Species Interactions' study described by Chapman et al. (2018a) which was designed to investigate interactions between ryegrass functional types and clover presence or absence that may affect ranking of cultivars for DMY. All combinations of the two nitrogen fertiliser treatments ('low' and 'high') and two white clover treatments (sown without clover i.e. ryegrass monoculture and denoted 'minus clover', and sown with clover i.e. ryegrass/clover mixture and denoted 'plus clover') from that design were used for this analysis. Thus, data sets from this scale of evaluation were further delineated according to the respective $\mathrm{N}$ fertiliser and clover treatment combinations as follows: 'LP High $\mathrm{N}$ minus clover'; 'LP High N plus clover'; 'LP Low N minus clover'; 'LP Low N plus clover'.

The Species Interactions experiment was conducted at four sites, using the same design and treatments in all cases: Waikato (described in detail by Lee et al. 2018), Manawatu (Cosgrove et al. 2018a), Canterbury (Chapman et al. 2018b), and Southland (Stevens et al. 2018). The SP study was conducted immediately adjacent to the Species Interactions experiments at each site, and so was also repeated across 4 regions. Both the SP and Species Interactions experiments were conducted for three years, using the same seed lines for each cultivar, with 4 and 5 replicates respectively of each cultivar. The mean annual rates of $\mathrm{N}$ fertiliser applied in the SP trial and in the two $\mathrm{N}$ treatments in Species Interactions/LP are presented in Table 1. In the SP trial, N was applied at each DM harvest at rates equivalent to $3 \%$ of the trial mean DM removed at the previous harvest, except for the Manawatu site $(2.5 \%$ of DM removed).

The ryegrass cultivars and associated endophytes used in all trials are described in Chapman et al. (2018a). Briefly, they included two mid-season heading diploids (Commando AR37 and Kamo AR37); four late-season heading diploids (Prospect AR37, Alto AR37, Abermagic AR1 and One50 AR37, in order of heading date); and two late-season heading tetraploids (Base AR37 and Bealey NEA2/6).

In SP, a strip of herbage was mown from the length of each plot to $\sim 4 \mathrm{~cm}$ height using a standard push lawn mower, fresh weight of clippings was recorded, and sub-samples were taken for assessing DM\%. All four SP trials were grazed by dairy cattle until grazing height first reached the $4 \mathrm{~cm}$ DM harvest height in preferentially-grazed plots, after which grazing ceased and all remaining herbage was removed to $4 \mathrm{~cm}$ height by lawn mower to achieve a common residual state across all plots. During dry summers, if herbage mass failed to reach a minimum trigger of $1000 \mathrm{~kg}$ $\mathrm{DM} / \mathrm{ha}$ available for harvest within 40 days of the previous sampling, DMY was measured anyway and grazing/mowing was applied as usual. Between 8 and 10 harvests were conducted per year, depending on

Table 1 Mean nitrogen fertiliser rates (kg N/ha per year) applied in the trials used in the analysis. The high and low $\mathrm{N}$ treatments in LP were based on the range seen in regional statistics (from DairyBase) for $\mathrm{N}$ fertiliser use on New Zealand dairy farms in 2010/11 (Chapman et al. 2018a).

\begin{tabular}{lccc}
\hline & \multirow{2}{*}{$\begin{array}{c}\text { Small plot } \\
\text { (SP) }\end{array}$} & \multicolumn{2}{c}{ Large plot (LP) } \\
\cline { 3 - 4 } & & High N & Low N \\
\hline Waikato & 362 & 211 & 42 \\
Manawatu & $445^{1}$ & 163 & 50 \\
Canterbury & 288 & 314 & 101 \\
Southland & 530 & 225 & 50 \\
\hline
\end{tabular}

${ }^{1} \mathrm{~N}$ applied at $2.5 \%$ of DM harvested. All other SP sites: $3 \%$. 
location and seasonal conditions for pasture growth. In contrast, grazing of LP plots continued until the mean residual height across all plots reached $\sim 4 \mathrm{~cm}$, and mowing was only used sporadically to remove dung or urine patches avoided by animals if these began to compromise overall grazing efficiency at subsequent harvests.

Several variables were measured in the LP experiment at each site. A description of the measurement methods, and full results, can be found in each of the site papers cited above. Only seasonal DMY data are included in this analysis, since the FVI reports only seasonal DM performance values: total annual yield is not included as a trait in the FVI.

\section{Data analysis}

A total of 14 seasonal DMY data sets were available for all trials. 'Seasons' were aligned with FVI delineations for five seasons per year: winter; early spring; late spring; summer; and autumn (Table 2). Three years' worth of data were available for all seasons except for winter, where DMY data were available only in years 2 and 3 after sowing (Table 2).

Linear functional regression analysis (reduced major axis, Genstat Model 2) with SP dry matter yield as the dependent variable and DMY of all four LP treatment combinations as independent variables was used to investigate relative yields between scales. The reduced major axis method estimates the slope as the geometric mean of the regression coefficients from regressions of $\mathrm{Y}$ on $\mathrm{X}$ and $\mathrm{X}$ on $\mathrm{Y}$. Abermagic was excluded from the regression analysis because its mean (across all regions) ranking position among the eight cultivars changed significantly, from mid-range in SP to bottom of the range in LP. Omission of this cultivar therefore removed any effects of substantial re-ranking due to scale of evaluation within regions from the analysis. Results are presented as mean intercept and slope with associated $95 \%$ confidence intervals and P-values as well as the $\mathrm{R}^{2}$ value of the model.

All analyses were performed using Genstat for Windows $19^{\text {th }}$ edition. Significance is declared $\mathrm{P} \leq 0.05$.

\section{Results}

The main effect of cultivar on average (across all four regions) seasonal DM yield was statistically significant in the SP trial, and in all 4 treatment combinations in the LP trial (data not shown). Regression plots using the means for all 14 seasons are presented in Figure 1; all were statistically significant at $\mathrm{P}<0.001$. The associated regression statistics are shown in Table 3.

Across all regions and treatments, the mean slope of the relationship between SP DMY and LP DMY was 0.733 , and SP DMY explained $64.4 \%$ of the variation in LP DMY (Table 3). Slopes were significantly less than 1 in twelve of the 16 region $\times$ treatment combinations (all rows in Table in which the upper 95\% confidence limit is less than 1), not significantly different from 1 in two of the 16 combinations ( $95 \%$ confidence interval includes 1), and significantly greater than 1 in two of the 16 combinations (lower 95\% confidence limit exceeds 1). The slope of the relationship was greater in Canterbury (mean 0.998) than in the other three regions (means $0.665,0.666$ and 0.605 for Waikato, Manawatu and Southland respectively; Table 3 and Figure 1). Mean $\mathrm{R}^{2}$ values were lowest for Manawatu (49.9) followed by Waikato (63.3), Canterbury (69.2) and Southland (75.1) (Table 3).

The slope of the relationship between SP DMY and LP DMY was significantly greater for the High N LP treatment than the Low N LP treatment (i.e. the LCL for High $\mathrm{N}$ and the UCL for Low $\mathrm{N}$ did not overlap) in five of the 8 region $\times$ clover treatment combinations (Table 3). Similarly, the slope was significantly greater for the plus clover treatment compared to the minus clover treatment in three of the 8 region $\times$ nitrogen

Table 2 Delineation of five 'seasons' by months, and of the years for which data were used in the analyses for each region

\begin{tabular}{lcccccc}
\hline Region & & \multicolumn{5}{c}{ Season ${ }^{1}$} \\
\cline { 3 - 7 } & & $\begin{array}{c}\text { Winter } \\
(\mathbf{2})^{\mathbf{2}}\end{array}$ & $\begin{array}{c}\text { Early spring } \\
\mathbf{( 3 )}\end{array}$ & $\begin{array}{c}\text { Late spring } \\
\mathbf{( 3 )}\end{array}$ & $\begin{array}{c}\text { Summer } \\
\text { (3) }\end{array}$ & $\begin{array}{c}\text { Autumn } \\
\text { (3) }\end{array}$ \\
\hline Waikato & Months & May, Jun & Jul, Aug & Sep, Oct & Nov-Jan & Feb-Apr \\
& Years & 2013,14 & $2012-14$ & $2012-14$ & $2012-14$ & $2012-14$ \\
\hline Manawatu and & Months & Jun, Jul & Aug, Sep & Oct, Nov & Dec-Feb & Mar-May \\
Canterbury & Years & 2013,14 & 2012-14 & 2012-14 & 2012-14 & $2012-14$ \\
\hline Southland & Months & Jun, Jul & Aug, Sep & Oct, Nov & Dec-Feb & Mar-May \\
& Years & 2014,15 & $2013-15$ & $2013-15$ & $2013-15$ & $2013-15$
\end{tabular}

${ }^{1}$ Following conventions of the Forage Value Index, Chapman et al. (2017)

2 Distribution by season of the 14 datasets used in the analysis 


\section{A Minus clover}

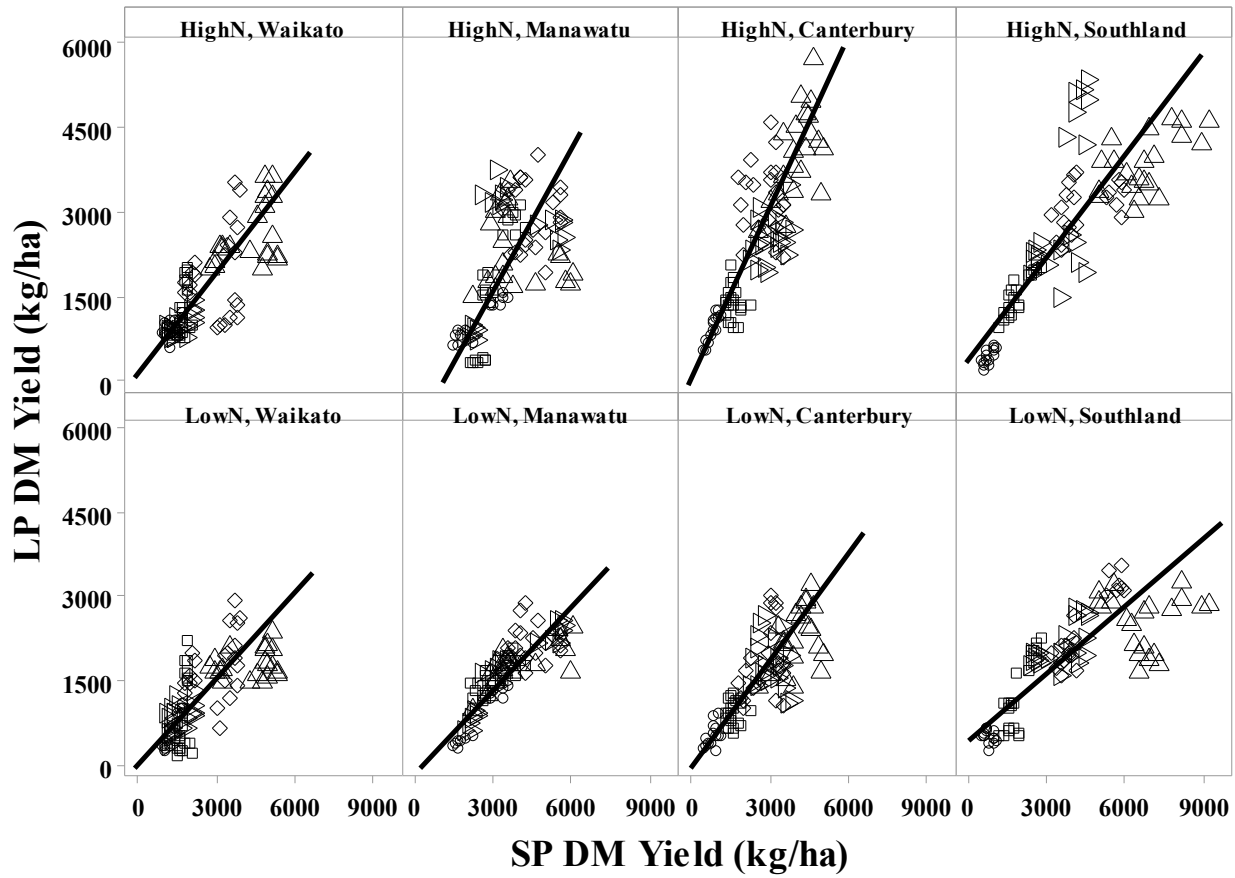

\section{Season}

- WI

$\square$ ES

$\diamond \mathbf{L S}$

$\triangle \mathbf{S U}$

$\triangleright \mathbf{A U}$

\section{B Plus clover}

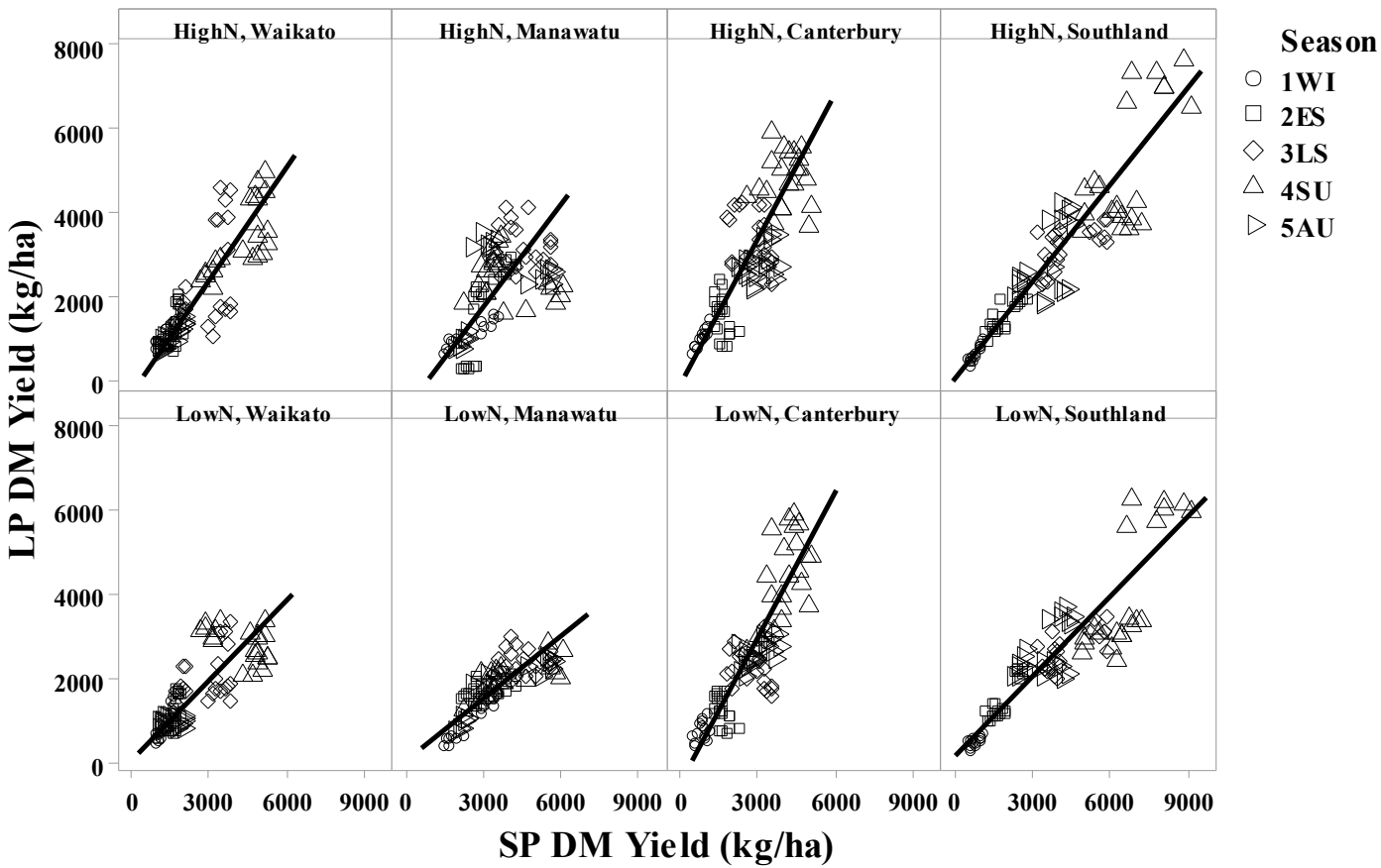

Figure 1 Relationshipsbetweenseasonaldrymatter(DM)yield(kgDM/ha) ofsevenperennialryegrasscultivarsmeasuredattwo'scales' ofevaluation:smallplot(SP)orlargeplot(LP)infourregions. PasturesinthelatterreceivedeitherHighorLowratesofnitrogen(N) fertiliser application, and sown either without white clover (A, 'minus clover') or with white clover (B, 'plus clover'). $\mathrm{WI}=$ winter; $\mathrm{ES}=$ early spring; $\mathrm{LS}=$ late spring; $\mathrm{SU}=$ summer; $\mathrm{AU}=$ autumn. 
combinations (Table 3). Mean slopes for High $\mathrm{N}$ and Low $\mathrm{N}$ were 0.845 and 0.621 respectively; and for plus clover versus minus clover 0.825 and 0.642 respectively. The mean (across 4 regions) slope increased progressively from the Low $\mathrm{N}$ minus clover treatment (0.510), to Low N plus clover (0.733), High $\mathrm{N}$ minus clover (0.774) and High N plus clover (0.917) (Table 3).

\section{Discussion}

Significant differences among cultivars were observed at both scales of comparison, so both were able to successfully discriminate between high- and lowperforming cultivars for DMY. All of the relationships between DMY measured at SP and LP scales were statistically significant indicating good general agreement between them in representing trends in cultivar performance. Across regions, $\mathrm{N}$ treatments and clover treatments, yield in SP explained over two thirds (range $32.2 \%$ to $84.6 \%$ ) of the variation in yield in LP. Nonetheless, for three quarters of the region $\times$ treatment combinations included in the analysis, the slope of the relationship between the two scales of evaluation was significantly less than 1 , indicating that the magnitude of yield differences between cultivar ranking positions was less at the larger plot scale than in the smaller, very intensively managed plots.

The most important factor contributing to the deviation from a 1:1 relationship was nitrogen supply. Variation in nitrogen supply was the single common feature across all treatment combinations in LP. The contribution from $\mathrm{N}$ fertiliser is obvious (Table 1), but there was also a substantial contribution via biological nitrogen fixation (BNF) by clover at all sites except Manawatu where virtually no clover was present in pastures in the Species Interactions experiment beyond the first year (Cosgrove et al. 2018a).

At the other three sites, total pasture DMY was greater in the grass/clover mixture treatments than in the ryegrass monocultures, by $\sim 2.4 \mathrm{t} \mathrm{DM} / \mathrm{ha} /$ year under the Low $\mathrm{N}$ fertiliser treatment, and by $\sim 1.2 \mathrm{t} \mathrm{DM} / \mathrm{ha}$ in the High $\mathrm{N}$ treatment (Chapman et al. 2018c). Using the detailed data for pasture botanical composition available from the Waikato and Canterbury sites, Chapman et al. (2018c) estimated that two thirds of this yield advantage came directly from the clover DMY adding to (rather than substituting for) ryegrass DMY. No re-ranking interactions between ryegrass cultivar and clover presence/absence were observed at any sites in the Species Interactions experiment and only sporadic scaling interactions were recorded. Hence clover presence per se should have played little part in the SP-LP relationships explored here: we assume all cultivars benefitted equally from the presence of clover at the larger-plot scale of evaluation.

The other one third of the yield advantage to the plus

Table 3 Linear regression statistics for the relationship between SP seasonal dry matter yield (independent variable) and LP dry matter yield (dependent variable, for all combinations of nitrogen and clover treatments) in four regions.

\begin{tabular}{|c|c|c|c|c|c|c|}
\hline Region & Nitrogen treatment & Clover treatment & Slope & $95 \% \mathrm{LCL}^{1}$ & $95 \% \mathrm{UCL}^{2}$ & $\mathbf{R}^{2}$ \\
\hline \multirow[t]{4}{*}{ Waikato } & High & Minus & 0.608 & 0.516 & 0.693 & 64.0 \\
\hline & & Plus & 0.895 & 0.787 & 1.015 & 75.6 \\
\hline & Low & Minus & 0.512 & 0.444 & 0.597 & 49.5 \\
\hline & & Plus & 0.645 & 0.557 & 0.744 & 64.2 \\
\hline \multirow[t]{4}{*}{ Manawatu } & High & Minus & 0.841 & 0.739 & 0.984 & 33.1 \\
\hline & & Plus & 0.834 & 0.723 & 0.971 & 32.2 \\
\hline & Low & Minus & 0.492 & 0.443 & 0.557 & 69.8 \\
\hline & & Plus & 0.495 & 0.441 & 0.563 & 64.5 \\
\hline \multirow[t]{4}{*}{ Canterbury } & High & Minus & 1.028 & 0.943 & 1.125 & 72.7 \\
\hline & & Plus & 1.171 & 1.050 & 1.297 & 67.5 \\
\hline & Low & Minus & 0.633 & 0.556 & 0.703 & 62.4 \\
\hline & & Plus & 1.159 & 1.029 & 1.307 & 74.2 \\
\hline \multirow[t]{4}{*}{ Southland } & High & Minus & 0.618 & 0.551 & 0.712 & 70.8 \\
\hline & & Plus & 0.767 & 0.697 & 0.837 & 84.6 \\
\hline & Low & Minus & 0.403 & 0.358 & 0.457 & 64.3 \\
\hline & & Plus & 0.631 & 0.559 & 0.698 & 80.7 \\
\hline
\end{tabular}

${ }^{1} 95 \%$ lower confidence limit; ${ }^{2} 95 \%$ upper confidence limit 


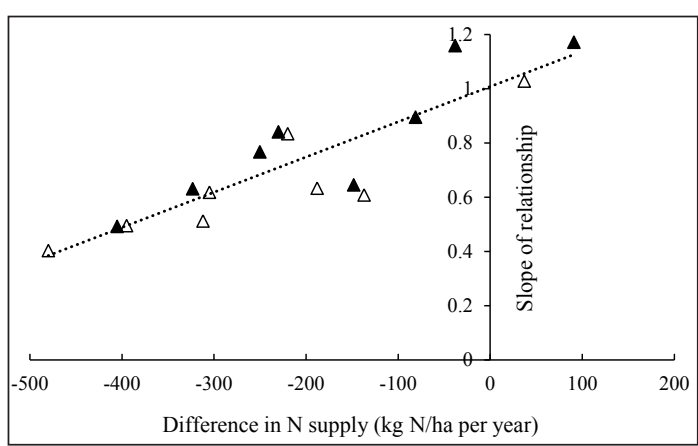

Figure 2 Relationship between the difference in total nitrogen supply (fertiliser applied, plus estimated biological nitrogen fixation) and the slope of the relationship between dry matter yield measured at two 'scales' of evaluation in four regions. $\boldsymbol{\Delta}=$ plus clover; $\triangle=$ minus clover. Regression equation: $y=$ $0.0013 x+1.021 ; R^{2}=0.766$

clover treatments in Species Interactions came from additional ryegrass DMY facilitated by transfer of BNF from clover to grass. Assuming that about 50\% of $\mathrm{BNF}$ is transferred to the grass component of the mixture under grazing (Ledgard 1991), the estimated total BNF in the High N treatment was 56 and $54 \mathrm{~kg} \mathrm{~N} /$ ha/year at Waikato and Canterbury respectively, and in the Low N treatment 164 and $150 \mathrm{~kg} \mathrm{~N} / \mathrm{ha} /$ year at the respective sites (Chapman et al. 2018c). Total N supply in the plus clover treatments at three of the four sites would therefore have been substantially greater than that shown in Table 1. Estimated total $\mathrm{N}$ supply from both sources was 267 and $206 \mathrm{~kg} \mathrm{~N} / \mathrm{ha} /$ year for High and Low $\mathrm{N}$ respectively in Waikato; 225 and $50 \mathrm{~kg} \mathrm{~N} /$ ha/year in Manawatu (from fertiliser only, since clover was largely absent at this site); 368 and $251 \mathrm{~kg} \mathrm{~N} / \mathrm{ha} /$ year in Canterbury; and 280 and $207 \mathrm{~kg} \mathrm{~N} / \mathrm{ha} /$ year in Southland (using the mean estimated BNF rates for Waikato and Canterbury calculated by Chapman et al. 2018c).

The relationship between the difference in total $\mathrm{N}$ applied in LP (as above) relative to SP (the first column in Table 1) and the mean slope of the DMY relationship between SP and LP - i.e. the 'slope of the slopes' - is shown in Figure 2. The regression explains $77 \%$ of the variation in the relationships between DMY measured at different scales of evaluation, with an intercept $=$ 1.02. Thus, the SP scale of evaluation provides a good approximation of relative yield differences under different managements; and indicates that in situations where expected yield differences do not emerge at different scales of comparison, management, especially nitrogen inputs, are the main source of the discrepancy, not factors related to plant genotypes.

This conclusion appears to hold across a wide range of environments, as represented by the four regions included in this study. It then begs the question, what is the appropriate scale of evaluation for estimating yield differences that could be expected on farm? The analysis presented here suggests this is really a question about the appropriate $\mathrm{N}$ inputs to use to mimic farm practice: and therefore that 'scale' effects, as we sought to define in this study, are dominantly nitrogen effects. However, we note that several other factors besides $\mathrm{N}$ supply differed between the 'scales' of evaluation compared here, including physical plot size $\left(10 \mathrm{~m}^{2}\right.$ in SP, versus 65 to $90 \mathrm{~m}^{2}$ in LP), grazing intensity, and the use of mowing (greater in LP). Scaling effects observed here cannot be attributed directly to any further specific factor(s) beyond $\mathrm{N}$ supply. Other factors such as the greater control over management of inputs and grazing/ mowing in SP compared with LP, and more influence of the direct effects of animals on pastures such as excreta patches, grazing uniformity, treading damage and plant pulling (uprooting) (Watkin \& Clements 1978) in LP compared with SP could also have been involved, but are impossible to quantify.

It is important to note that this analysis was based on only one small plot trial in each region. There is considerable variability in relative cultivar performance between trials (Easton et al. 2001; Kerr et al. 2012) and several trials are required to provide accurate ranking information. To our knowledge there are no other instances where matching trials have been conducted at different scales to conduct similar analyses to the one reported here. Therefore, caution is required when extrapolating more generally. Nonetheless, the cultivar rankings in the SP trials reported here were very similar to those produced from the larger NZPBRA database, with the notable exception of Base AR37 which was bottom in both SP and LP, but is highly ranked in the NZPBRA database.

\section{Conclusions}

Relative DMY of different cultivars at larger physical scales of comparison are well-predicted by relative differences measured in small plot comparisons when the total $\mathrm{N}$ supply is similar between the two scales. Higher-yielding cultivars are therefore seen to be more responsive to $\mathrm{N}$ supply: where $\mathrm{N}$ is more abundant, the difference in yield between ranking positions stretches out compared with situations where $\mathrm{N}$ supply is limited.

In this study, the Low $\mathrm{N}$ minus clover treatment in LP was probably not very relevant to farm practice, since farmers will almost always include white clover in seed mixtures and additional $\mathrm{N}$ will be supplied by BNF. The mean (across all regions) $\mathrm{N}$ content of herbage in this treatment was $2.6 \%$ of DM (Cosgrove et al. 2018b). This is below the critical concentration for perennial ryegrass growth of $3.2 \%$ (Smith et al. 1985) indicating the yield potential of higher-performing 
cultivars probably could not be expressed. However, the other three treatment combinations represent a reasonable range in current $\mathrm{N}$ fertiliser inputs and clover contribution in New Zealand dairy pastures, including situations where clover 'crashes' as in the Manawatu Species Interactions experiment.

The average total $\mathrm{N}$ supply across all regions (including BNF) in the High N treatment in LP was $270 \mathrm{~kg} \mathrm{~N} /$ ha per year (228 from fertiliser), versus 406 $\mathrm{kg} \mathrm{N} / \mathrm{ha}$ applied per year as fertiliser in SP. The N fertiliser rates used in LP High $\mathrm{N}$ were at least $25 \mathrm{~kg}$ $\mathrm{N} /$ ha above the New Zealand dairy farm average usage at the time this experiment was initiated (2012), and these can be expected to fall further as farmers adjust to environmental regulations being implemented to reduce nitrate leaching rates under dairying (Chapman et al. 2019). This points to a difference in $\mathrm{N}$ supply of 150 to $250 \mathrm{~kg} \mathrm{~N} / \mathrm{ha}$ per year between farm practices that will emerge over the next decade and current management protocols used in trial systems such as NFVT, and therefore realised yield gains from ryegrass breeding that may be 0.7 to 0.8 of the gains they predict.

\section{ACKNOWLEDGEMENTS}

This work was funded by New Zealand dairy farmers through DairyNZ Inc. (Project RD1414; Waikato and Canterbury) and the AgResearch Strategic Science Investment Fund (Manawatu and Southland). The small plot trials reported here were managed and measured by John Higgins, Prue Taylor, Nigel Johnston, Kevin Knowler and Brooke Bryson, and the large plot trials by DairyNZ and AgResearch technical teams. We gratefully acknowledge their substantial contribution. Expert additional statistical analysis support from Harold Henderson, AgResearch and constructive comments from two anonymous reviewers are also gratefully acknowledged.

\section{REFERENCES}

Chapman DF, Bryant JR, Olayemi ME, Edwards GR, Thorrold BS, McMillan WH, Kerr GA, Judson G, Cookson T, Moorhead A, Norriss M. 2017. An economically based evaluation index for perennial and short-term ryegrasses in New Zealand dairy farm systems. Grass and Forage Science 72: 1-21.

Chapman DF, Lee JM, Rossi L, Cosgrove GP, Stevens DR, Crush JR, King WM, Edwards GR, Popay AJ. 2018a. Implications of grass-clover interactions in dairy pastures for forage value indexing systems. 1. Context and rationale. New Zealand Journal of Agricultural Research 61: 119-146.

Chapman DF, Rossi L, Lee JM, Edwards GR, Popay AJ, Wilson DJ, Bell NL. 2018b. Implications of grass-clover interactions in dairy pastures for forage value indexing systems. 4. Canterbury. New Zealand
Journal of Agricultural Research 61: 204-229.

Chapman DF, Crush JR, Lee JM, Cosgrove GP, Stevens DR, Rossi L, Popay AJ, Edwards GR, King WM. 2018c. Implications of grass-clover interactions in dairy pastures for forage value indexing systems. 6. Cross-site analysis and general discussion. New Zealand Journal of Agricultural Research 61: 255284.

Chapman D, Pinxterhuis I, Ledgard S, Parsons AJ. 2019. White clover or nitrogen fertiliser for dairying under nitrate leaching limits? Animal Production Science Published online 20 December 2018: doi 0.1071/AN18577

Cosgrove GP, Popay AJ, Taylor PS, Wilson DJ, Alders LT, Bell NL. 2018a. Implications of grass-clover interactions in dairy pastures for forage value indexing systems. 3. Manawatu. New Zealand Journal of Agricultural Research 61: 174-203.

Cosgrove GP, Lee JM, Chapman DF, Stevens DR, Rossi L, King WM, Edwards GR. 2018b. Metabolisable energy concentration in perennial ryegrass pastures: multi-site analysis of effects of cultivar, nitrogen fertiliser, and white clover content. Journal of New Zealand Grasslands 80: 235-241.

Easton HS, Baird DB, Cameron NE, Kerr GA, Norriss M, Stewart AV. 2001. Perennial ryegrass cultivars: Herbage yield in multi-site plot trials. Proceedings of the New Zealand Grassland Association 63: 183188.

Harmer M, Stewart AV, Woodfield DR. 2016. Genetic gain in perennial ryegrass forage yield in Australia and New Zealand. Journal of New Zealand Grasslands 78: 133-138.

Kerr GA, Chapman DF, Thom ER, Matthew C, van der Linden A, Baird DB, Johnston E, Corkran JR. 2012. Evaluating perennial ryegrass cultivars: improving testing. Proceedings of the New Zealand Grassland Association 74: 127-136.

Ledgard SF. 1991. Transfer of fixed nitrogen from white clover to associated grasses estimated using ${ }^{15} \mathrm{~N}$ methods in swards grazed by dairy cows. Plant and Soil 131: 215-223.

Lee JM, Matthew C, Thom ER, Chapman DF. 2012. Perennial ryegrass breeding in New Zealand: an industry perspective. Crop and Pasture Science 63: 107-127.

Lee JM, Chapman DF, Wims CM, Griffiths WM, Popay AJ, Wilson DJ, Bell NL. 2018. Implications of grassclover interactions in dairy pastures for forage value indexing systems. 2. Waikato. New Zealand Journal of Agricultural Research 61: 147-173.

Smith GS, Cornforth IS, Henderson HV. 1985. Critical leaf concentration for deficiencies of nitrogen, potassium, phosphorus, sulphur and magnesium in perennial ryegrass. New Phytologist 101: 393-409. 
Stevens DR, Bryson BJ, Ferguson CM, Wilson DJ, Bell NL, Aalders LT, Popay AJ. 2018. Implications of grass-clover interactions in dairy pastures for forage value indexing systems. 5. Southland. New Zealand Journal of Agricultural Research 61: 230-254.
Watkin, BR, Clements RJ. 1978. The effects of grazing animals on pastures. In: Wilson JR. Ed. Plant relations in pastures. Melbourne, Australia: CSIRO. pp. 273-289. 